\title{
Correction to: Sequence and structural variation in the genome of the Biomphalaria glabrata embryonic (Bge) cell line
}

Nicolas J. Wheeler', Nathalie Dinguirard', Joshua Marquez², Adrian Gonzalez², Mostafa Zamanian', Timothy P. Yoshino ${ }^{1}$ and Maria G. Castillo ${ }^{2^{*}}$

\section{Correction}

Following publication of the original article [1], the authors reported an error in figure 1 :

The incorrect Figure 1 published is:

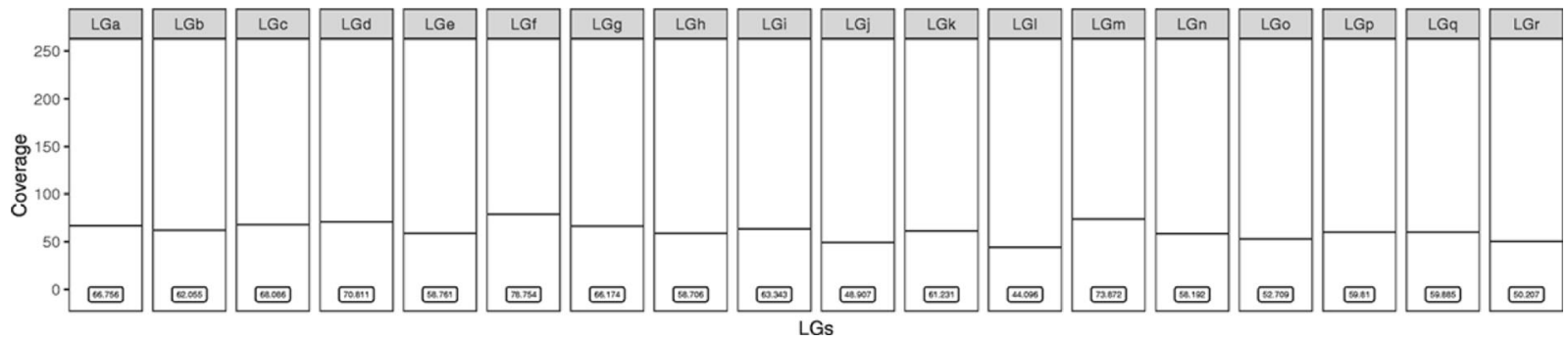

The correct Figure 1 is:

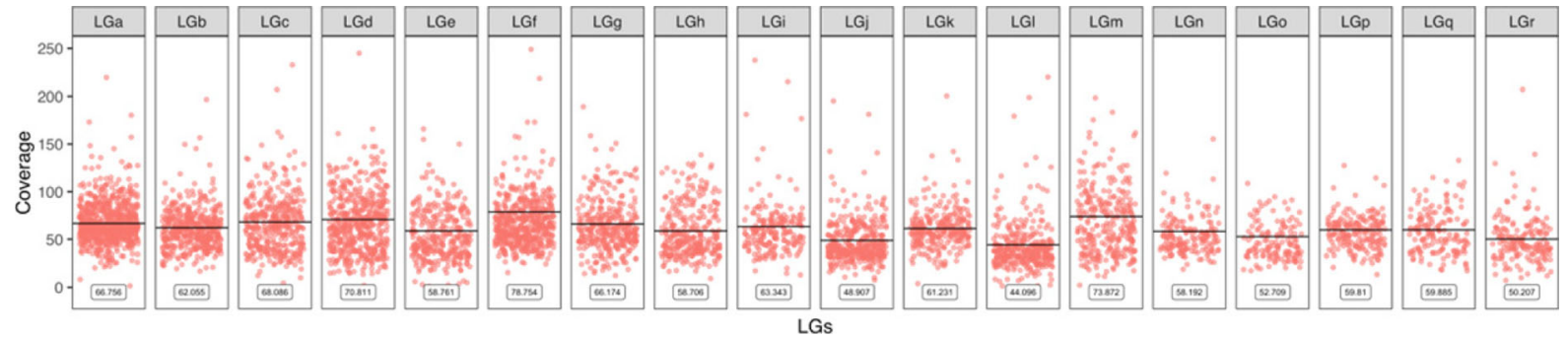

\footnotetext{
* Correspondence: mcastill@nmsu.edu

2Department of Biology, New Mexico State University, Las Cruces, NM, USA

Full list of author information is available at the end of the article
} 


\section{Author details}

${ }^{1}$ Department of Pathobiological Sciences, School of Veterinary Medicine,

University of Wisconsin, Madison, WI, USA. ${ }^{2}$ Department of Biology, New

Mexico State University, Las Cruces, NM, USA.

\section{Published online: 29 October 2018}

\section{Reference}

1. Wheeler NJ, et al. Sequence and structural variation in the genome of the Biomphalaria glabrata embryonic (Bge) cell line. Parasit Vectors. 2018;11:496 https://doi.org/10.1186/s13071-018-3059-2. 